\title{
A não participação nas aulas de Educação Física na perspectiva de alunos do ensino fundamental $\mathbf{I I}^{\mathbf{1}}$
}

\author{
Jairo Antônio da Paixão* \\ Otávio Soares de Oliveira**
}

\begin{abstract}
Resumo
O estudo investigou a não participação nas aulas de Educação Física na perspectiva de alunos do ensino fundamental II. A partir de uma investigação de natureza qualitativa, foi possível afirmar que a parcela de alunos que se recusa a participar das aulas adere à prática regular de atividades físico-esportivas em ambientes extraescolares como em academias, clubes e nos bairros onde residem. Dentre os motivos, encontram-se a falta de materiais pedagógicos e estruturais na escola, repertório pouco variado dos conteúdos trabalhados e, ainda, a indiferença por parte do professor diante do quadro apresentado. Já os alunos que participam acabam por assumir o protagonismo nas atividades físico-esportivas, fator esse que tem propiciado a segregação pelos mais habilidosos e conflitos relacionados à categoria gênero.
\end{abstract}

Palavras-chave: Escola; Educação Física; Não participação discente.

\section{Non-participation in Physical Education classes in the student perspective of elementary school II}

\begin{abstract}
The study investigated the non-participation in Physical Education classes in the student perspective of elementary school II. From a qualitative research, it was possible to affirm that the learners who refuse to participate in the classes join the regular practice of physical sporting activities outside of school in environments as gyms, clubs and spaces in the neighborhoods where they live. Among the reasons, it was found the lack of pedagogical and structural materials in school, a little varied repertoire of the contents and yet the indifference on the part of the teacher in front to the picture presented. On the other side, the students who participate end up take over the protagoni in the physical sport activities, factor that has led to the segregation by the more skilled and conflicts related to gender.
\end{abstract}

Keywords: School; Physical Education; Student's non-participation.

\section{Introdução}

Atualmente, entende-se a Educação Física como uma prática de intervenção pedagógica que trata de temas advindos da Cultura Corporal de Movimento, que contribui para o processo de formação dos sujeitos que irão reproduzir, produzir, transformar e partilhar as diversas formas de manifestações corporais como os jogos, esportes, ginásticas, lutas, atividades rítmicas e expressivas, exercícios físicos $\mathrm{e}$ as demais práticas que correspondem à cultura corporal de movimento, que compõe seus conteúdos de ensino (DARIDO, 2004). Cumpre destacar que a Cultura Corporal de Movimento, ao envolver a relação entre corpo, natureza e cultura, configura-se como um conhecimento que vai sendo construído e reconstruído ao longo dos tempos, circunscrevendo a própria produção humana e sua historicidade.

Dentre as disciplinas que compõem o currículo da educação básica, nomeadamente, a Educação Física se configura como aquela pela qual

\footnotetext{
*Endereço eletrônico: jairopaixao@ufv.br

***Endereço eletrônico: otavio1soares@yahoo.com.br
}

os alunos demonstram grande interesse (BRANDOLIN, 2010; ALMEIDA et al., 2011). Certamente, esse interesse e, em alguns casos, a predileção por parte dos alunos, relacionam-se diretamente com a especificidade desse componente curricular como o espaço físico em que, geralmente são realizadas as aulas, o movimento como eixo norteador dos conteúdos trabalhados, somado às sensações de liberdade vivenciadas pelos alunos. No entanto, o fato de a Educação Física aparecer entre os componentes curriculares dos mais apreciados, não lhe confere posição entre aqueles considerados mais valorizados pelos alunos na escola (MARTINS; FREIRE, 2013). Nem sempre os estudantes vêm importância naquilo que se aprende durante as aulas de Educação Física, resultando em desinteresse pelas aulas (DARIDO, 2004).

Nessa perspectiva, é possível perceber a coexistência de grupos de alunos que se recusam a participar das atividades propostas pelo professor, nas aulas, ao longo do período letivo. Seguindo esse pressuposto, Millen Neto et al. (2010) afirmam que a escolha por não participarem das aulas de 
Educação Física, ao contrário das demais disciplinas que acontecem em sala de aula, é explícita, devido ao fato de a Educação Física desenvolver atividades de fruição corporal, as quais demandam movimentos por parte daqueles que se envolvem nas mesmas. Nesse sentido, o tempo destinado às aulas acaba sendo ocupado com outras atividades por esses alunos, como ouvir músicas, uso do celular, bate papos e contínuas caminhadas pela área interna da escola que, em alguns casos, acabam tumultuando a rotina e a organização da escola em questão.

A não participação nas aulas relaciona-se a fatores como os horários em que ocorrem, as relações de gênero, discriminação quanto ao nível de habilidades motoras entre os colegas de turma, a estrutura física destinada às aulas práticas, a não identificação e/ou interesse pelos conteúdos trabalhados pelo professor e, ainda, a ausência de planejamento das aulas (JACÓ, 2008; TEIXEIRA; MOLETTA, 2011; GUIMARÃES et al., 2001; MARZINEK, 2004; DARIDO, 2004, 2011). Ressalta-se também o desenvolvimento de um único conteúdo pelo professor, durante um período considerável, no decorrer do ano letivo. Nesse caso, as modalidades de esportes tradicionais são as privilegiadas, com destaque ao futsal (OLIVEIRA, 2006). Cabe destacar que, se o conteúdo esporte for trabalhado na perspectiva da aptidão física, essa situação pode se agravar, uma vez que são exacerbadas características técnicas e táticas, e suprimidas as de natureza lúdicas e inclusivas no trato do referido conteúdo nas aulas. (OLIVEIRA, 2005).

A partir do final do ensino fundamental, já se observa $o$ início de uma não participação concreta durante as aulas de Educação Física (BETTI; ZULIANE, 2002; ALMEIDA; CAUDURO, 2007; CAPARROZ; BRACHT, 2007). Trata-se de uma fase em que os alunos apresentam nível considerável de criticidade e, assim, expõem mais suas ideias e opiniões sobre diferentes situações e fatos, o que inclui as aulas de Educação Física (AQUINO, 2005).

Tendo em vista o quadro delineado, o presente estudo teve como objetivo investigar a não participação nas aulas de Educação Física sob a perspectiva de alunos que se encontravam nos anos finais do ensino fundamental II em uma escola pública da cidade de Ouro Preto, MG.

\section{Metodologia}

Considerando o fenômeno analisado, a trilha científica foi conduzida a partir das diretrizes da abordagem qualitativa de pesquisa (TRIVIÑOS, 1995; LAKATOS; MARCONI, 2007). A opção pela abordagem predominantemente qualitativa se explica pelo fato de ela conceber os sujeitos como participantes ativos da construção do conhecimento a partir da emissão de opiniões, pensamentos, atitudes que compõem a visão da realidade que os cerca (CHIZZOTTI, 2006).

Os dados coletados foram obtidos a partir do emprego de duas técnicas: observação (SAMPIERI; COLLADO; LUCIO, 2013) e grupo focal (GATTI, 2012). A primeira consistiu no registro sistemático a partir da elaboração de categorias observáveis presentes no comportamento e condutas dos sujeitos da pesquisa. Foram consideradas as seguintes categorias: relação entre os alunos não participantes e o professor da disciplina Educação Física; relação entre os alunos não participantes e os participantes das aulas de Educação Física e, ainda, entre os alunos não participantes e a ambiência da escola. As observações ocorreram, nos momentos das aulas de Educação Física, com cinco turmas, no período de 20 a 31 de outubro de 2014, totalizando 10 observações.

O grupo focal configura-se como uma modalidade de entrevista, em que se trabalha com grupos de número reduzido de participantes, os quais, por intermédio de um pesquisador experiente, primam pela interação entre os integrantes a partir de comentários, ideias e questões apresentadas em pauta (GATTI, 2012). Foi realizado um encontro com os participantes do grupo focal nas dependências da escola, no horário destinado às aulas de Educação Física. O grupo amostral foi constituído de 10 alunos de ambos os sexos (um aluno e nove alunas), regularmente matriculados no $8^{\circ}$ e $9^{\circ}$ ano do ensino fundamental II de uma escola pública da rede municipal de ensino, localizada na cidade de Ouro Preto, MG. No intuito de assegurar uma amostra representativa para o presente estudo, o número de sujeitos foi determinado pelo pesquisador no viés de amostragem por conveniência. A entrevista realizada como grupo focal foi registrada em um aparelho de gravador digital Sony IC recorder ICD-PX720.

Vale ressaltar que, na fase de seleção dos integrantes do grupo amostral, foi fundamental o apoio do professor da disciplina Educação Física, que repassou as informações sobre os alunos que mantinham uma recusa permanente em participar das aulas. Dentre a parcela de alunos que não participavam das aulas, havia aqueles que vinham se 
recusando em participar desde o início do ano letivo em que se deu a pesquisa, bem como em períodos anteriores a mesma.

A opção, neste estudo, por um grupo amostral restrito, embora representativo, justificou pela modalidade de entrevista coletiva empregada com vistas a definir o foco na aquisição de informações qualitativas. Deste modo, os critérios de inclusão foram alunos que se encontravam regularmente matriculados no $8^{\circ}$ e no $9^{\circ}$ ano do ensino fundamental II e que mantinham uma recusa permanente em participar das aulas de Educação Física, bem como a aceitação em fazer parte da pesquisa, mediante assinatura do Termo de Consentimento Livre e Esclarecido (TCLE). Os critérios de exclusão foram sujeitos que não se encontravam na situação descrita, a recusa da assinatura do TCLE e o não interesse em participar do estudo.

A opção por alunos que se encontravam neste segmento da Educação Básica $\left(8^{\circ}\right.$ e $9^{\circ}$ ano do ensino fundamental II) foi fundamentada, não somente pelos dados apontados pela realidade nas aulas de Educação Física, mas também por estudos realizados por Betti e Zuliane (2002), Paiano (2006) e Pereira e Moreira (2005) que analisaram a participação de alunos nas aulas de Educação Física. Esses estudos revelam que, nos anos que compreendem o ensino fundamental I, são raros os casos de não participação dos alunos, os quais demonstram grande interesse pelas atividades desenvolvidas nas aulas. A partir do ensino fundamental II e, de forma mais acetuada, no ensino médio, a não participação é mais recorrente (PEREIRA; MOREIRA, 2005; PAIANO, 2006).

No tratamento dos dados coletados, foi empregada a técnica de análise interpretativa de conteúdo que, de acordo com Bardin (2011), se refere a um conjunto de técnicas de análise das comunicações visando obter, por procedimentos sistemáticos e objetivos de descrição do conteúdo das mensagens, indicadores quantitativos ou não que permitem a inferência de conhecimentos relativos às condições de produção/recepção (variáveis inferidas) destas mensagens. Sobretudo, a análise de conteúdo possibilitou identificar características presentes nas falas dos integrantes do grupo focal. Os dados foram categorizados e quantificados a partir da aproximação das respostas. Posteriormente, essas características forneceram as bases para a edificação de categorias de análise do fenômeno em questão. Dessa forma, os resultados e discussão apresentados, no presente estudo, organizam-se a partir das categorias de análise apresentadas na sessão Resultados e Discussão.

A pesquisa foi aprovada pelo Comitê de Ética em Pesquisa da Universidade Federal de Ouro Preto, ofício CEP No $\mathrm{N}^{\circ}$. 872.102, de 16 de novembro de 2014.

\section{Resultados e discussão}

A discussão dos resultados desenvolveu-se através da triangulação entre os dados obtidos por meio das observações realizadas nas aulas, as entrevistas com os participantes do grupo focal, a produção bibliográfica relacionada à temática em questão e, também, as posições assumidas pelos autores da investigação em relação ao problema abordado. A partir das categorias de análise estabelecidas por meio do objetivo do estudo, esta sessão se apresenta em duas partes: a primeira aborda a relação dos alunos com as atividades físico-esportivas e a segunda analisa a participação dos alunos nas atividades físico-esportivas nas aulas.

\section{A relação dos alunos com as atividades físico- esportivas}

A partir do discurso de saúde e qualidade de vida no contexto atual, parece ter se convertido em lugar-comum a percepção generalizada entre pessoas de diferentes faixas etárias dos benefícios obtidos através de um estilo de vida ativo. Nesse contexto, a prática de atividades físico-esportivas ganha relevo no cotidiano das pessoas como um hábito. Na escola, mais precisamente, nas aulas de Educação Física, é possível abordar inúmeros aspectos no trato com as atividades físicoesportivas, como as características motoras, culturais, de sociabilidade, cooperação, cidadania, aptidões físicas entre outras. Pesquisas na área evidenciam que essa situação se ratifica, de forma unânime, nos relatos dos alunos ao confirmarem o prazer e a satisfação ao praticar atividades físicoesportivas (SOUSA; DANIEL, 2010; ALMEIDA et al., 2011).

No entanto, a escola não foi apontada, por esses mesmos alunos, como espaço privilegiado para o desenvolvimento dessas práticas corporais. Em seus depoimentos, foi evidenciada a prática físico-esportiva pela totalidade dos alunos. Para essa finalidade, esses sujeitos utilizam espaços extraescolares como ruas, praças e academias de ginástica como se pode perceber nos relatos abaixo destacados. "[...] se for numa academia, ainda vai, 
mas na escola tem alguns brutamontes, que acertam a bola na sua cara. Tenho trauma disso, aí eu prefiro ficar fora". E ainda, “[...] as aulas na escola são sem graça. Há uma preferência maior dos meninos, eles gostam de futebol".

De acordo com os resultados verificados por Sousa (2010), a prática de atividade física está relacionada, muitas vezes, com as habilidades dos alunos, sendo que os que não apresentam tais habilidades ficam às margens da aula, contribuindo para o aumento e manutenção da parcela de alunos que não participam das aulas de Educação Física na escola. Esses dados suscitam questões que demandam atenção. Primeiramente, pelo fato de se tratarem de depoimentos advindos de alunos regularmente matriculados numa escola pública. Em sua maioria, são alunos que, pelo nível socioeconômico, concebem a escola como espaço privilegiado para o acesso às diferentes manifestações das práticas corporais de forma sistematizada. Sobre essa situação, Vago (2009) ressalta que a escola é, sobretudo, lugar de circular, de reinventar, de estimular, de transmitir, de produzir, de usufruir, enfim, de praticar cultura. $\mathrm{O}$ autor complementa a ideia ao afirmar que nove de cada dez estudantes são acolhidos pela escola pública no Brasil. Cumpre destacar ainda, nessas falas, posicionamentos que denotam conflitos relacionados à categoria gênero.

Tendo em vista os tempos e espaços na escola, as aulas de Educação Física compreendem momentos da vida escolar de maior interação entre meninos e meninas, os quais, muitas vezes, confrontam níveis de habilidades motoras necessárias à realização de determinadas práticas corporais. Em muitas escolas, ainda é comum a separação por sexo nas aulas de Educação Física. Chama a atenção que, nem sempre a divisão dos espaços e tempos de aula se dá de forma equânime, cabendo às meninas o menor espaço com atividades físico-esportivas que, em alguns casos, distanciamse daquelas realizadas pelos meninos numa mesma aula (ALTMANN, et al., 2012). Embora se reconheça que a adoção de turmas mistas não garanta o término das hierarquizações da categoria de gênero tem-se, por outro lado, que as formas de organizações das aulas de Educação Física por turmas separadas por sexo devam ser desprezadas pela escola e pelos professores do referido componente curricular.

Cabe destacar que o fato de as meninas, tal como os meninos, não terem as mesmas oportunidades e condições de vivenciar as diversas práticas corporais nas aulas, contribui para que elas participem, de forma menos efetiva nas aulas, chegando, em alguns casos, a subjugarem do direito de participarem das aulas de Educação Física (MOURÃO; DUARTE, 2007). Essa situação foi evidenciada nos relatos das participantes, como uma das alunas que fez alusão à diferenciação no trato dado a meninos e meninas nas aulas e, consequentemente, nas oportunidades de participação nas atividades físico-esportivas propostas pelo professor. Essa aluna chega a afirmar, de forma categórica, que, na grande maioria das vezes, nos momentos em que decorrem as aulas, ela "[...] nem passa próximo da quadra".

Cumpre salientar que os sujeitos deste estudo, são predominantemente formados por alunas e advém de turmas que têm como responsável pela disciplina Educação Física um professor. Não obstante, esse dado faz sentido quando analisado na perspectiva dos estudos de gênero na Educação Física escolar (GOELLNER, 2001; ALTMANN, et al., 2012). Uma aluna citou o fato de o professor encarar a situação de hierarquização de gêneros nas aulas com considerável indiferença, como mostra o seu depoimento: “[...] o professor está tão acostumado que nem liga mais".

Com o movimento renovador na educação, especificamente na Educação Física, iniciado na segunda metade da década de 1980, intensificaramse as discussões de cunho pedagógico, o que resultou no surgimento de várias abordagens para o ensino da Educação Física, dentre as quais buscavam superar a visão biológica da Educação Física na escola, viabilizando novos olhares para a área a partir das ciências humanas (ARAÚJO, 2014). Ainda assim, a realidade percebida na escola deixa dúvidas acerca da efetivação de mudanças na prática pedagógica do professor e, por conseguinte, na forma de se abordar os conteúdos junto aos alunos nas aulas de Educação Física.

Nessa direção, é importante assinalar que hoje nas escolas, as aulas de Educação Física não são ministradas de acordo com o que estabelece os currículos oficiais, como os Parâmetros Curriculares Nacionais, o Conteúdo Básico Comum, bem como as propostas curriculares elaborados por determinados estados por meio de suas respectivas secretarias. Desta forma, na maioria das vezes, os professores não seguem uma metodologia que levem os alunos a se interessarem pelas aulas (FREITAS, et al., 2016). Neste contexto, os elementos pedagógicos acabam se distanciando dos objetivos a serem alcançados, e a aula acaba por se 
tornar um espaço de lazer para os alunos que têm mais habilidades. Em decorrência disso, o desinteresse, a não participação dos alunos e a evasão das aulas de Educação Física ainda são fatos comuns dentro das escolas públicas (POZZOBON; FOLLE, 2007).

Subvertendo esse quadro, durante a entrevista, na maior parte dos depoimentos, ficou evidente o envolvimento dos alunos em uma ou mais atividades físico-esportivas extraescolares, em espaços como praças, localizadas nos bairros, clubes e academias de ginástica. Com frequência que varia de duas vezes semanal, a todos os dias da semana, foram destacadas diferentes práticas corporais como dança, skate, ginásticas, futebol, corridas e caminhadas. Uma das participantes ressaltou que a prática de atividades físico-esportivas fora da escola se mostra muito mais interessante para ela. Ao contrário do que normalmente ocorre na escola, quando ela pratica alguma atividade físico-esportiva no seu bairro sempre pode contar com "[...] gente a fim de ajudar uns aos outros". Trata-se de uma alusão à perspectiva da competitividade e sobrepujança que marcou a própria história da Educação Física e que, infelizmente, ainda prevalece nas aulas de Educação Física em muitas instituições escolares (DARIDO; RANGEL, 2011; BARBOSA, 2007). Acrescenta-se a isso o imaginário social construído e reforçado, ao longo dos tempos na sociedade, sobre Educação Física; reforçado pelos meios de comunicação de massa e pelos próprios professores de Educação Física atuantes nos diferentes segmentos que compõem a Educação Básica.

No próximo item, será discutida a categoria de análise na qual é destacada a participação dos alunos em atividades físico-esportivas no cotidiano das aulas de Educação Física.

\section{Participação nas atividades físico-esportivas nas aulas de Educação Física}

A discussão sobre a participação ou não de alunos nas aulas de Educação Física demanda considerar aspectos relacionados ao espaço ocupado por esse componente curricular na escola. Assim, vê-se que, nos contextos e nos cenários em que se apresenta a Educação Física escolar, prevalece ainda a concepção de uma mera atividade física extracurricular, desvinculada da proposta pedagógica da escola como normatizada pelas Leis de Diretrizes e Bases da Educação Nacional 4.024/61 e 5.692/71 (SOUZA JUNIOR; DARIDO, 2009). Essa situação vem implicando de forma negativa, não somente em função da ocorrência de mudanças de ordem didático-pedagógica, como também daquelas relacionadas às estruturas físicas e materiais para as aulas de Educação Física na escola (BETTI et al., 2011; GASPARI et al., 2006).

Tendo em vista que os sujeitos considerados nesse estudo integravam um grupo de alunos que se recusava a participar das aulas, ao aludir ao tema participação nas atividades físico-esportivas no decorrer das aulas de Educação Física, o grupo fez menção a uma série de fatores que, segundo eles, reforçavam a não participação.

A restrição de conteúdos - com ênfase no esporte - trabalhados pelo professor nas aulas ganha relevo nos depoimentos dos alunos entrevistados como se pode ver em: “[...] você só tem três tipos de escolhas: peteca, futsal ou vôlei". Eles completaram de maneira enfática que esse fato torna as aulas desinteressantes e muito previsíveis, considerando que a sua ocorrência prevalece ao longo de todo o ano letivo.

Ao se analisar a hegemonia do conteúdo do esporte nas aulas, destaque deve ser dado no campo das políticas públicas para o setor da Educação Física e do Esporte no Brasil, em que a Educação Física escolar foi integrada ao sistema esportivo brasileiro, tendo como uma de suas mais importantes funções promover a iniciação esportiva, no sentido de identificar talentos que pudessem, no futuro, participar das equipes representativas do país no cenário esportivo internacional (BRACHT, 2010).

Dentre as diversas proposições, decorrentes do movimento renovador ocorrido na década de 1980, mencionado anteriormente, destaca-se a diversificação dos conteúdos nas aulas. Nessas reflexões, os professores deveriam ser capazes de superar o desenvolvimento restrito de determinados conteúdos, como as tradicionais modalidades esportivas, e desta forma, avançar com o desenvolvimento organizado das diversas manifestações corporais que compõem o universo da cultura corporal, que perpassam as questões do corpo e do movimento, dentre elas, destaque para a ginástica, a dança, a capoeira, as lutas, os jogos e brincadeiras, entre outros conteúdos deixados em segundo plano ao longo da história da Educação Física na escola (SOARES et al. 1992; BRASIL, 1998; RODRIGUES; DARIDO, 2011). Soma-se a esse fato, a falta de materiais pedagógicos na escola. Um dos alunos explica que, na maioria das vezes, os colegas de turma que participam das aulas combinam entre si e trazem os próprios materiais 
pedagógicos como bola e peteca para a escola, como se apresentam alguns depoimentos em destaque. "[...] quando avisa que vai ter uma dessas atividades a gente traz de casa, porque não tem na escola". E "[...] há pouco tempo, tivemos que comprar a peteca pra jogar".

Cabe assinalar aqui que estudos feitos por Gaspari et al. (2006) mostram que as escolas, de maneira especial, as da rede pública, enfrentam problemas como a falta de materiais e de instalações para as aulas de Educação Física. Trata-se de uma condição que não somente compromete a prática pedagógica do professor como também torna as aulas menos estimulantes para os alunos (REZER, 2007).

Parece possível afirmar que, uma das primeiras condições para garantir a participação dos alunos das aulas de Educação Física consiste na melhoria da qualidade destas aulas que não podem continuar a ser uma simples repetição dos processos de iniciação esportiva vivenciados pelos alunos durante o Ensino Fundamental, tampouco o simples "rola bola" sem intervenção do professor, já criticados em diversas pesquisas na área (DARIDO; SANCHES NETO, 2005; DARIDO; SOUZA JÚNIOR, 2007).

O referido cenário da Educação Física escolar impõe ao professor um permanente desafio de diversificar os conteúdos trabalhados, proporcionar aulas que despertem o interesse dos alunos, desprovido de material pedagógico, de infraestrutura e, muitas vezes, do reconhecimento e do apoio da escola. Em uma investigação realizada por Fonseca Filho et al. (2011), constatou-se que, na perspectiva dos alunos, dentre os aspectos relacionados com a melhoria das aulas de Educação Física, destaque foi dado à infraestrutura dos espaços em que essas aulas eram realizadas na escola.

Uma vez que o grupo não participa das atividades físico-esportivas trabalhadas durante o período das aulas, tornou-se imperativo conhecer as formas empregadas por esses alunos na ocupação desse tempo disponível, no interior da escola. O relato a seguir foi feito pelo grupo no decorrer da discussão dessa questão. "[...] andamos pela escola, dormimos, conversamos e ficamos fazendo o dever de outra matéria".

O depoimento dos alunos também revelou que a situação, nas aulas, se altera nos dias em que estão presentes, na escola, os acadêmicos dos cursos de licenciatura em Educação Física matriculados na disciplina Estágio Curricular Supervisionado. A fala dos participantes do grupo focal foi consonante com resultados de estudos sobre o tema (BERTINI JUNIOR; TASSONI, 2013; MARTINS; FREIRE, 2013; VEDOVATTO; SOUZA NETO, 2015), reveladores que, na medida em que o professor proporciona diferentes conteúdos, aumentam, de forma significativa, as vivências nas aulas, a motivação e interação entre os pares nas práticas corporais proporcionadas.

Não obstante a isso, acrescenta-se o trânsito desses alunos pela escola. Fato esse que, em alguns momentos, chega a tumultuar outras turmas que se encontram na sala de aula. Essa situação foi percebida nas observações realizadas no período em que se deu a coleta de dados. "[...] com os estagiários eu gostava". "Eram atividades diferentes"

Porém, subvertendo os dados apresentados, verifica-se que as mudanças configuram uma situação de resistência e embates por parte dos alunos que compõem o grupo não participante das aulas como mostram algumas falas.

“[..] quando chegam os estagiários, eles te obrigam a fazer a aula, mandam fazer muita coisa também. Assim, não dá vontade em participar."

"[...] a gente acostuma com a rotina de ficar dentro de sala, eles chegam e querem mandar, ai não participamos. [...] nunca teve ninguém mandando na Educação Física."

"[...] eles fazem uma aula dentro de sala. Quem já viu Educação Física dentro de sala! ? Eles passam trabalho de Educação Física."

A partir desses depoimentos, fazem-se necessárias algumas considerações.

Embora estudos demonstrem a contribuição do estágio curricular supervisionado à prática pedagógica do professor que atua na Educação Básica, o qual recebe os alunos da licenciatura e os supervisiona (PIMENTA, 2011), essa contribuição não implica em mudanças nas proporções que se fazem necessárias, para sanar dilemas que prevalecem na Educação Física escolar. Também não é essa a finalidade dessa disciplina. No entanto, sem considerar a vertente niilista, destaca-se aqui uma perspectiva que sinaliza estratégias educativas para a minimização dos efeitos negativos provenientes de fatores que levam a não participação nas aulas do referido componente curricular. Nessa perspectiva, emerge como oportuno destacar que o verbo mandar foi empregado muitas vezes nos relatos com o sentido 
de autoridade por parte dos estagiários para com o grupo de alunos que não participam das atividades propostas nas aulas. As contradições presentes nos relatos conferem atenção aos dados, haja vista a complexa e delicada relação que, geralmente, se estabelece entre estagiários e alunos da Educação Básica. Isso leva a pensar não em autoridade por parte dos estagiários, mas sim, na representatividade dos novos atores com propostas de conteúdos e atividades diferenciadas, o que, por outro lado, desestrutura a zona de conforto, uma situação acordada entre o professor e o grupo de alunos não participante.

Esta posição assumida pelo grupo de alunos não participantes pode ser entendida como uma forma de resistência às propostas de diversificação do conteúdo pelos estagiários. Sobretudo, trata-se de resistência em prol de uma situação de conforto erigida por essa parcela de alunos não participantes, ao longo dos períodos letivos nas aulas de Educação Física.

\section{Considerações finais}

A partir dos resultados obtidos, neste estudo, e considerando as suas limitações metodológicas, é possível afirmar que a parcela de alunos que se recusa a participar das aulas de Educação Física, ainda que em nível de senso comum, reconhece a importância da prática regular de atividade física para a manutenção da saúde e bem-estar.

Os depoimentos dos alunos sobre a não participação nas aulas é suficiente para referendar os fatores por eles apontados, como a falta de materiais pedagógicos e estruturais na escola para as aulas, um repertório pouco variado dos conteúdos trabalhados ao longo do período letivo e, ainda, a indiferença por parte do professor diante do quadro apresentado.

Esses mesmos alunos aderem à prática regular de atividades físico-esportivas em ambientes extraescolares, como em academias, em clubes, em espaços nos próprios bairros onde residem. Assim, entende-se o interesse dos mesmos em praticar atividades físico-esportivas, que compõem o conteúdo que, na escola, fica a cargo da disciplina Educação Física proporcionar aos alunos.

Como consequência da postura adotada pelo professor diante das precárias condições proporcionadas pela escola para o desenvolvimento das aulas de Educação Física, o grupo de alunos interessados em participar acaba por assumir o protagonismo na condução das atividades físicoesportivas, fator esse que propicia a segregação pelos mais habilidosos, bem como conflitos relacionados à categoria gênero.

Ao considerar as finalidades da Educação Física no processo de formação dos alunos nos diferentes segmentos que compõem a educação básica, a recusa de uma parcela de alunos em participar efetivamente das aulas desse componente curricular no interior da escola, deve ser entendida como um fenômeno que merece atenção por parte da escola no intuito de detectar e desenvolver propostas que venham amenizar e/ou solucionar a problemática. Isso porque, já não é mais possível manter uma visão unilateral do fenômeno analisado neste estudo que se coloca presente no dia a dia nas aulas de Educação Física como a recusa do aluno em tomar parte ao que está sendo oportunizado no ambiente de ensino aprendizagem.

Trata-se de uma tomada de decisão que se configura como eixo norteador para balizar a direção se quer mover e quais são as características da rota que vem sendo proposta para a Educação Física na escola. Somente assim, a Educação Física poderia assumir efetivamente o status de componente curricular, como prevê a legislação brasileira, cumprindo sua parcela do papel destinado ao processo de formação do aluno ao longo da Educação Básica.

\section{Notas}

1 Esse artigo consiste na versão ampliada do Trabalho apresentado no XII Congresso Nacional de Educação (EDUCERE), 2015, na área temática Didática: teorias, metodologias e práticas (GT 05). A pesquisa teve como órgão financiador o CNPQ no período de 01 de agosto de 2014 a 31 de julho de 2015.

\section{Referências}

ALMEIDA, A. B.; TUCHER, G.; ROCHA, C. A. Q.; PAIXÃO, J. A. Percepção discente sobre a educação física escolar e motivos que levam à sua prática. Revista Mackenzie de Educação Física e Esporte, São Paulo, v. 10, n. 2, p. 109-116, 2011.

ALMEIDA, P.C.; CAUDURO, M.T. O desinteresse pela Educação Física no ensino médio. Lecturas: Educación Física y Deportes, Buenos Aires, v. 11, 
n. 106, mar., 2007. Disponível em <http://www.efdeportes.com/efd106/odesinteressep elaeducacaofisicanoensinomedio.htm>. Acesso em 7 mai. 2015.

ALTMANN, H. MARIANO, M.; UCHOGA, L. A. R.; Corpo e movimento: produzindo diferenças de gênero na educação infantil. Revista Pensar a Prática. Goiânia, v. 15, n. 2, p. 272-301, abr./jun. 2012.

ARAÚJO, R. A. S. A Educação Física na formação inicial: prática pedagógica e currículo. Gráfica e Editora: Maranhão, 2014.

AQUINO, J. G. (org.). Erro e fracasso na escola: alternativas teóricas e metodológicas. São Paulo: Summus, 2005.

BARBOSA, C. L. A. Educação Física Escolar: da alienação à libertação. $5^{\mathrm{a}}$ ed. Petrópolis: Vozes, 2007.

BARDIN, L. Análise de conteúdo. Trad. Luís Antero Reto e Augusto Pinheiro. $4^{\mathrm{a}}$ ed. Lisboa: Edições 70, 2011.

BERTINI JUNIOR, N.; TASSONI, E. C. M. A educação física, o docente e a escola: concepções e práticas pedagógicas. Revista Brasileira de Educação Física e Esporte, São Paulo, v. 27, p. 467-483, 2013.

BETTI, M.; ZULIANI, L. R. Educação física escolar: uma proposta de diretrizes pedagógicas. Revista Mackenzie de Educação Física e Esporte. V.I, n.1, p. 73-81, 2002.

; FERRAZ, O. L.; DANTAS, L. E. P. B. T. Educação Física Escolar: estado da arte e direções futuras. Revista Brasileira de Educação Física e Esporte. v. 25, p. 105-115, 2011.

BRACHT, V. A educação física no ensino fundamental. In: I SEMINÁRIO NACIONAL: CURRÍCULO EM MOVIMENTO. 2010. 14 f. Belo Horizonte. Anais... Belo Horizonte, 2010.

BRANDOLIN, F. A percepção dos alunos sobre a educação física no ensino médio. Dissertação (Mestrado em Educação) - Faculdade de Educação, Universidade Federal do Rio de Janeiro - UFRJ, 2010 .
CAPARROZ, F.E.; BRACHT, V. O tempo e o lugar de uma didática da educação física. Revista Brasileira de Ciências do Esporte, Campinas, v. 28, n. 2, p. 2137, 2007.

CHIZZOTTI, A. Pesquisa em Ciências Humanas e Sociais. $2^{\mathrm{a}}$ ed. São Paulo: Cortez, 2006.

DARIDO, S. C. A Educação Física na escola e o processo de formação dos não praticantes de atividade física. Revista Paulista de Educação Física, São Paulo, v. 18, n.1, p. 44-58, 2004.

; RANGEL, I. A Educação Física na escola: implicações para a prática pedagógica. $2^{\mathrm{a}}$ ed. Rio de Janeiro: Guanabara Koogan, 2011.

; SANCHES NETO, L. O contexto da educação física na escola. In: DARIDO, S. C.; RANGEL, I. C. A. (org). Educação física na escola: implicações para a prática pedagógica. Rio de Janeiro: Guanabara Koogan, 2005. p. 50-61.

; SOUZA JÚNIOR, O. M. Para ensinar educação física: possibilidades de intervenção na escola. Campinas, SP: Papirus, 2007.

FONSECA FILHO, G. S.; MARINHO, G. M.; ALVES, J. M.; OLIVEIRA, D. A. S.; FAGUNDES, J. L. C. Percepção dos alunos de uma escola pública em relação às aulas de educação física. In: ENCONTRO ESTADUAL DE DIDÁTICA E PRÁTICA DE ENSINO, 4., 2011, Goiânia. Anais... Goiânia: Endipe, 2011. p. 57-70.

FREITAS, J. S. et al. A identidade da Educação Física escolar sob o olhar dos alunos do $5^{\mathrm{a}}$ ano do ensino fundamental I. Pensar a Prática, Goiânia, v. 19, n. 2, abr./jun. 2016.

GASPARI, T. C.; SOUZA JUNIOR, O.; MACIEL, V.; IMPOLCETTO, F. M.; VENÂNCIO, L.; IORIO, L.; THOMMAZO, A.; DARIDO, S. C. A realidade dos professores de Educação Física na escola: suas dificuldades e sugestões. Revista Mineira de Educação Física, v. XIV, p. 109-137, 2006.

GATTI, B. Grupo focal na pesquisa em ciências sociais e humanas. Brasília: Líber Livro, 2012.

GOELLNER, S. V. Gênero, educação física e esportes. In: VOTRE, S. Imaginário $e$ 
representações sociais em educação física, esporte e lazer. Rio de Janeiro: Editora Gama Filho, 2001.

GUIMARÃES, A; PELLINI, F; ARAÚJO, J; MAZZINI, J. Educação Física Escolar: Atitudes e Valores. Revista Motriz. Rio Claro: Vol. 7, n.1, p. 17-22, Jan. 2001.

JACÓ, J. Educação física e adolescência: "Professor, não vou participar da aula!". Trabalho de conclusão de curso (Graduação em Educação Física) UNICAMP - Campinas, 2008.

LAKATOS, E. M; MARCONI, M. Metodologia do trabalho científico. $7^{\mathrm{a}}$. ed. São Paulo: Atlas, 2007.

MARTINS, A.B.R.; FREIRE, E. S. O Envolvimento dos alunos nas aulas de Educação Física: um estudo de caso. Revista Pensar a Prática, Goiânia, GO, v. 16, p. 760-774, 2013.

MARZINEK, A. A motivação de adolescentes nas aulas de Educação Física. Universidade Católica de Brasília, Programa de Pós-Graduação Stricto Sensu em Educação Física. Brasília - DF, 2004.

MILLEN NETO, A. R.; CRUZ, R. P.; SALGADO, S. S.; SOARES, A. J. G.; CHRISPINO, R. F. Evasão escolar e desinteresse dos alunos nas aulas de educação física. Revista Pensar a Prática, Goiânia, GO, v. 13, n. 2, p. 115, 2010.

MOURÃO, L. N.; DUARTE, C. P. Representações de adolescentes femininas sobre os critérios de seleção utilizados para a participação em aulas mistas de educação física. Revista Movimento, Porto Alegre, v. 13, n. 1, p. 37-56, jan./abr. 2007.

OLIVEIRA, V. Consenso e Conflito: Educação Física Brasileira. $2^{\mathrm{a}}$ ed. Rio de Janeiro: Shape, 2005. 206 p.

SP: Brasiliense, 2006.

O que é Educação Física? São Paulo -

PAIANO, R. Possibilidades de orientação da prática pedagógica do professor de educação física: situações de desprazer na opinião dos alunos. Revista Mackenzie de Educação Física e Esporte, São Paulo, v. 5, p. 47-58, 2006.

PEREIRA, R.; MOREIRA, E. A participação dos alunos do ensino médio em aulas de educação física: algumas considerações. Revista da Educação Física/UEM Maringá, v. 16, n. 2, p. 121-127, Nov. 2005.

PIMENTA, S.G. O estágio na formação de professores. $11^{\mathrm{a}}$ ed. São Paulo: Cortez, 2011.

POZZOBON, M. E.; FOLLE, A. Motivação nas aulas de jogos esportivos no contexto escolar. In: LAGO, C. (Org.). Reescrevendo a educação. Chapecó: Sinproeste, 2007. p. 109- 128.

REZER, R. Relações entre conhecimento e prática pedagógica no campo da Educação Física: pontos de vista. Revista Motrivivência, Santa Catarina, v. 19, p. 38-62, 2007.

RODRIGUES, H. A.; DARIDO, S. C. O livro didático na Educação Física escolar: a visão dos professores. Motriz, Rio Claro, v.17 n.1, p.48-62, jan./mar. 2011.

SAMPIERI, R. H.; COLLADO, C. F.; LUCIO, M. D. P. B. Metodologia de pesquisa, $5^{\mathrm{a}}$ ed. São Paulo: Artmed, 2013.

SOARES, C. et al. Metodologia do ensino de educação física. São Paulo: Cortez, 1992.

SOUZA JUNIOR, O.; DARIDO, S. C. Dispensas das aulas de Educação Física: apontando caminhos para minimizar os efeitos da arcaica legislação brasileira. Revista Pensar a Prática, Goiânia, v. 2, p. 22-32, 2009.

SOUSA, J. D.; DANIEL, M. M. da C. Importância da educação física escolar na visão dos alunos de uma escola pública. In: CONGRESSO NORTENORDESTE DE PESQUISA E INOVAÇÃO, 5, 2010, Maceió. Anais... Maceió: Connepi, p.1-7, mar. 2010.

SOUSA, L. F. N. I. Estratégias de aprendizagem e fatores motivacionais relacionados. Educação em Revista, n. 36, p. 95 - 107, 2010.

TEIXEIRA, F. A.; MOLETTA. A. F. Motivação nas aulas de educação física. In: X CONGRESSO NACIONAL DE EDUCAÇÃO - EDUCERE, Curitiba 2011.

TRIVIÑOS, A. N. S. Introdução à pesquisa em ciências sociais: a pesquisa qualitativa em 
educação. $4^{a}$ ed. São Paulo: Atlas, 1995.

VAGO, T. M. Pensar a educação física na escola: para uma formação cultural da infância e da juventude. Cadernos de Formação RBCE, p. 25-42, 2009.

\section{Sobre os autores}

Jairo Antônio da Paixão é Professor do Curso de Licenciatura da Universidade Federal de Viçosa (UFV). Coordenador do Grupo de Pesquisa e Estudos Pedagógicos em Educação Física (GEPEF). Docente do Programa de Pós-Graduação em Educação (PPGE/UFV).

Otávio Soares de Oliveira é Licenciado em Educação Física pela Universidade Federal de Ouro Preto, MG. Integrante do Grupo de Estudos Pedagógicos em Educação Física (GEPEF).

Recebido em março de 2016.

Aprovado em dezembro de 2016.
VEDOVATTO, I. D. F.; SOUZA NETO, S. Os desafios do Estágio Curricular Supervisionado em Educação Física na parceria entre Universidade e Escola. Revista Movimento. Porto Alegre, v. 21, p. 111-124, 2015. 